\title{
Defining the Caudal Ventral Striatum in Primates: Cellular and Histochemical Features
}

\author{
Julie L. Fudge ${ }^{1,2}$ and Suzanne N. Haber ${ }^{2}$ \\ Departments of ${ }^{1}$ Psychiatry, ${ }^{2}$ Neurobiology and Anatomy, and ${ }^{3}$ Neurology, University of Rochester Medical Center, \\ Rochester, New York 14642
}

\begin{abstract}
Afferents from the amygdala help to define the ventral striatum and mediate goal-directed behaviors. In addition to well known inputs to the classic ventral striatum, the amygdala also projects to the caudoventral striatum and amygdalostriatal area. We examined whether the primate caudoventral striatum and amygdalostriatal area can be considered part of the "ventral" striatum based on cellular and histochemical features found in the classic rostral ventral striatum. We used several histochemical stains, including calbindin-D28k, a marker of the shell compartment, acetylcholinesterase, substance $P$, tyrosine hydroxylase, and $\mathrm{Bcl}-2$, a marker of immature neurons, to examine this question. Our results indicate that the lateral amygdalostriatal area and caudoventral striatum are "striatal like" based on intermediate to high acetylcholinesterase and tyrosine hydroxylase levels. The lateral amygdalostriatal area is
\end{abstract}

The ventral striatum is considered the "limbic" region of the striatum because of inputs from brain regions mediating emotion. The amygdala, a prominent ventral striatal afferent, is critical to the acquisition of motivated behaviors (Cador et al., 1989). The amygdaloid inputs to the ventral striatum are well established, and the amygdala also projects to the caudal, ventral striatum, and amygdalostriatal area in the primate (Russchen et al., 1985; Fudge et al., 2002). Thus, based on amygdaloid inputs, there is a caudal "limbic-related" region of the striatum that includes the caudoventral putamen, the medial tail of the caudate nucleus, and the amygdalostriatal area. These striatal regions may also play a role in motivated responses.

One important issue is whether caudal striatal regions that receive amygdaloid input can be considered limbic based on other features of the ventral striatum. The classic ventral striatum is distinguished by a fundamentally different distribution of calbindin-D28k (CaBP), substance P (SP), tyrosine hydroxylase (TH), and acetylcholinesterase (AChE) compared with more dorsal sectors (Martin et al., 1991; Voorn et al., 1994; Meredith et al., 1996; Holt et al., 1997; Haber and McFarland, 1999). In particular, the ventral striatal "shell" stands out because of relatively low levels of CaBP (Meredith et al., 1996) and receives relatively restricted limbic afferents. The shell is also is unique in containing numerous cell islands, including the islands of Calleja.

Received July 23, 2002; revised Aug. 21, 2002; accepted Sept. 3, 2002.

This work is supported by National Institutes of Health Grants MH63291 (J.L.F., S.N.H.) and MH45573 (S.N.H.). We thank Hassan Jamil for technical assistance.

Correspondence should be addressed to Dr. Julie L. Fudge, Department of Psychiatry, University of Rochester Medical Center, 601 Elmwood Avenue, Rochester, NY 14642. E-mail: julie_fudge@urmc.rochester.edu.

Copyright @ 2002 Society for Neuroscience 0270-6474/02/2210078-05\$15.00/0 chemically similar to the shell, whereas the caudoventral striatum more closely resembles the striatum outside the shell. In contrast, the medial amygdalostriatal area is more related to the central amygdaloid nucleus than to the striatum. Bcl-2 immunoreactivity is associated with granular islands and mediumsized cells in the vicinity of the ventral striatum both rostrally and caudally. Together, the caudal ventral striatum has a histochemical and cellular organization similar to that of the rostral ventral striatum, consistent with their common innervation by the amygdala and other ventral structures. In addition, Bcl-2 is expressed in and near both poles of the ventral striatum, suggesting that these areas maintain a heightened capacity for growth and plasticity compared with other striatal sectors.

Key words: amygdala; amygdalostriatal area; Bcl-2; islands of Calleja; stria terminalis; ventral striatum
Although the functions of the cell islands are not known, they contain Bcl-2, a marker of neuronal immaturity, and are morphologically similar to young neurons (Meyer et al., 1989; Bernier and Parent, 1998).

The caudal ventral striatum and amygdalostriatal area form a broad, poorly defined area in the primate, which is separated from the central amygdaloid nucleus by the fibers of the stria terminalis. The boundary between the amygdalostriatal area and striatum is traditionally determined by AChE staining (DeOlmos, 1990). Like the ventral striatum, the amygdalostriatal area contains a variety of cell clusters and a heterogeneous distribution of several transmitters (DeOlmos, 1990; Pitkanen and Amaral, 1993; Heimer et al., 1999; Freedman and Shi, 2001). However, there are few data relating the distribution of $\mathrm{CaBP}$ and striatal transmitters to specific cellular subregions.

To determine whether the caudal ventral-related striatum and amygdalostriatal areas are part of the classic ventral striatum, we compared the following: (1) cytoarchitectural features relative to CaBP immunoreactivity, (2) the distribution of SP, AChE, and $\mathrm{TH}$ with respect to $\mathrm{CaBP}$-poor and $\mathrm{CaBP}$-rich boundaries, and (3) the distribution of Bcl-2 immunoreactivity and its association with specific cell islands.

\section{MATERIALS AND METHODS}

Definitions and nomenclature. The ventral striatal shell is defined by its relatively low $\mathrm{CaBP}$ immunoreactivity compared with the rest of the striatum (Meredith et al., 1996). Within the shell, the granular islands are clusters of small round neurons with darkly stained nuclei and include the islands of Calleja. The "parvicellular" islands contain slightly larger round cells with moderately stained nucleoli. Previous Golgi impregnation studies confirm that both of these cell types are neurons (Millhouse, 
1987; Meyer et al., 1989). We refer to the amygdalostriatal area as the region lateral to the stria terminalis, which contains low to intermediate AChE levels compared with the striatum (DeOlmos, 1990) (see Fig. 1J).

Histologic studies. Four adult macaques were used in these experiments, which were performed in accordance with National Institutes of Health guidelines. After initial anesthesia by intramuscular injection of ketamine $(10 \mathrm{mg} / \mathrm{kg})$, animals were deeply anesthetized and perfused through the heart with saline, followed by a $4 \%$ paraformaldehyde solution in $0.1 \mathrm{M}$ phosphate buffer, $\mathrm{pH} 7.4$. Serial sections of $50 \mu \mathrm{m}$ were cut on a freezing microtome and then processed individually for CaBP, TH, SP, AChE, and Bcl-2 protein or stained with cresyl violet. Additional immunostained compartments were counterstained with cresyl violet. Sections were placed in the primary antisera: anti-CaBP at 1:10,000, anti-TH at 1:10,000 (Chemicon, Temecula, CA), or anti-substance $\mathrm{P}$ at 1:200,000 (DiaSorin, Stillwater, MN), for 4 nights and then processed using the avidin-biotin reaction (Vector Laboratories, Burlingame, CA). $\mathrm{Bcl}-2$ protein immunostaining was performed using a modification of the method of Bernier and Parent (1998). Control sections omitting the primary antibody failed to show cell labeling. AChE staining was performed according to a modification of the Geneser technique(GeneserJensen and Blackstad, 1971).

Analysis. Master images were first charted from Nissl-stained sections under bright-field illumination. Adjacent sections processed for CaBP were then charted using a five-point scale [0, very low (background) levels; 1 , weak staining; 2 , moderate staining; 3, high staining; 4, very high staining). Charts from each case were entered into the computer (Adobe Illustrator 8.0; Adobe Systems, San Jose, CA) and superimposed according to landmarks. The cytoarchitectural features in each section could then be compared based on the pattern of $\mathrm{CaBP}$ staining. Data were confirmed with reference to additional sections processed for $\mathrm{CaBP}$ and counterstained with Nissl. Near adjacent sections immunoreacted for substance $\mathrm{P}, \mathrm{TH}, \mathrm{AChE}$, and $\mathrm{Bcl}-2$ were similarly charted and examined with reference to the Nissl- and CaBP-stained sections. The size of specific cell types was measured at $40 \times$ magnification using an objective reticule.

\section{RESULTS}

\section{Ventral striatum}

In adjacent Nissl-stained sections, the ependymal lining of the ventricle invades the striatum at the division of the shell and core (Fig. 1A). Within the CaBP-poor shell, a gradient of staining exists such that the dorsomedial shell has overall low to moderate CaBP levels with very low CaBP levels in the lateral shell (Fig. $1 B)$. In the transition between the core and shell, patches of moderate $\mathrm{CaBP}$ immunoreactivity alternate with strips relatively devoid of $\mathrm{CaBP}$ staining. Whereas many cell types are similar between the shell and core, fingerlike aggregates of small cells are oriented along the diagonal axis in the transition zone. These coincide with the CaBP-negative strips that course through the transition region.

The cells in the shell are generally smaller and more closely packed than in the ventral striatum outside the shell, as reported previously in the rodent (Hedreen, 1981). The dorsomedial shell has the smallest, most densely packed cells, and the ventral and lateral shell contain progressively larger cells with lighter staining and less packing density in Nissl-stained sections. Granular cell clusters are easily identified by their small $(6-10 \mu \mathrm{m})$, dark blue staining nucleoli (Fig. 1A, white arrows). The largest granular cell aggregate, the island of Calleja magna, reaches the ependymal lining of the ventricle in some sections (data not shown). The granular islands are $\mathrm{CaBP}$ negative but are encircled by dense CaBP-positive neuropil. Along the base of the brain, granular cell clusters are frequently in contact with parvicellular islands. The parvicellular cells are 10-14 $\mu \mathrm{m}$ in diameter and have varying levels of CaBP-immunoreactive neuropil, ranging from background to moderate levels.

High substance $\mathrm{P}$ immunoreactivity defines the dorsomedial shell, except for a small triangular region at the dorsal tip (Fig. $1 C$, asterisk). Bands of high immunoreactivity are prominent in the shell-core transition zone and overlay the fingerlike cell aggregates (which are CaBP poor). The highest substance $\mathrm{P}$ levels are in the granular islands (Fig. $1 C$, white arrow), in which two types of immunoreactive fibers are found. There is a coarse latticework of thick substance P-immunoreactive fibers with few punctae, which surround and invade the granular islands, in addition to a fine, meshwork of substance $\mathrm{P}$ fibers containing small boutons. Substance P-positive somata are also scattered among the granular islands. The parvicellular islands contain varying concentrations of fine punctate substance P-immunoreactive fibers. Substance P immunoreactive "woolly" fibers (Haber and Nauta, 1983) frequently encircle both granular and parvicellular islands.

Overall levels of TH staining are high throughout the ventral striatum (Fig. 1D). However, very high concentrations of THpositive fibers overlie the fingerlike aggregates of striatal cells in the transition zone. Dense concentrations of TH-positive fibers also surround and invade the granular cell islands, extending into adjacent parvicellular islands. The tip of the dorsomedial shell contains a triangular TH-poor patch (Fig. 1D, asterisk), which coincides with a substance P-poor-CaBP-rich area on adjacent sections (Fig. 1B,C, asterisk).

AChE staining is heterogeneous in the ventral striatum, as reported previously (Martin et al., 1991; Holt et al., 1996) (Fig. $1 E)$. The dorsomedial, ventral, and lateral shell contains intermediate AChE levels. In contrast, the transition zone between the shell and core contains lower AChE staining, which extends into the ventromedial caudate nucleus. The granular and parvicellular islands contain moderate to high AChE levels, as reported previously (Fallon et al., 1983; Heimer et al., 1999). Dorsolateral to the shell, AChE staining is generally higher.

\section{Caudoventral striatum-amygdalostriatal area}

In the lateral half of the amygdalostriatal area (Fig. $1 F$ ), there is a broad, irregular region of low $\mathrm{CaBP}$ staining that sweeps ventrally and laterally from the base of the globus pallidus (Fig. $1 G)$. Within this CaBP-poor region are patches of $\mathrm{CaBP}-$ immunoreactive cells and neuropil, similar to the CaBP-rich patches in the shell. In contrast, high CaBP levels predominate in the medial half of the amygdalostriatal area, following the stria terminalis dorsomedially toward the central nucleus and ventrally to the lateral ventricle. Several islands of medium-sized cells are consistently seen in the medial amygdalostriatal area and are also high in $\mathrm{CaBP}$ immunoreactivity. Lateral to the $\mathrm{CaBP}$-poor zone, the ventromedial putamen and the tail of the caudate nucleus contain high $\mathrm{CaBP}$ levels.

The main cells of the amygdalostriatal area are small, relatively darkly stained neurons in Nissl preparations, similar to those seen in the ventral striatal shell. Based on adjacent CaBP-stained sections, the majority of these are concentrated in the $\mathrm{CaBP}$-poor zone. In the medial (CaBP-enriched) amygdalostriatal area, there are a variety of cell types. Most prominent are islands of mediumsized cells that are encapsulated in fibers of the stria terminalis. Granular and parvicellular islands are also seen embedded in the fibers of the stria terminalis (Fig. $1 F$, white arrowheads). Islands of parvicellular neurons mixed with granule cells are the most common type of cell island, although small islands composed mainly of pure granule cells are also seen. These islands are found along the entire course of the stria terminalis: in the medial amygdalostriatal area, in the external capsule surrounding the caudoventral striatum, and beneath the posterior limb of the commissure. The CaBP-positive striatum (also delineated by high AChE staining) is composed primarily of loosely packed 

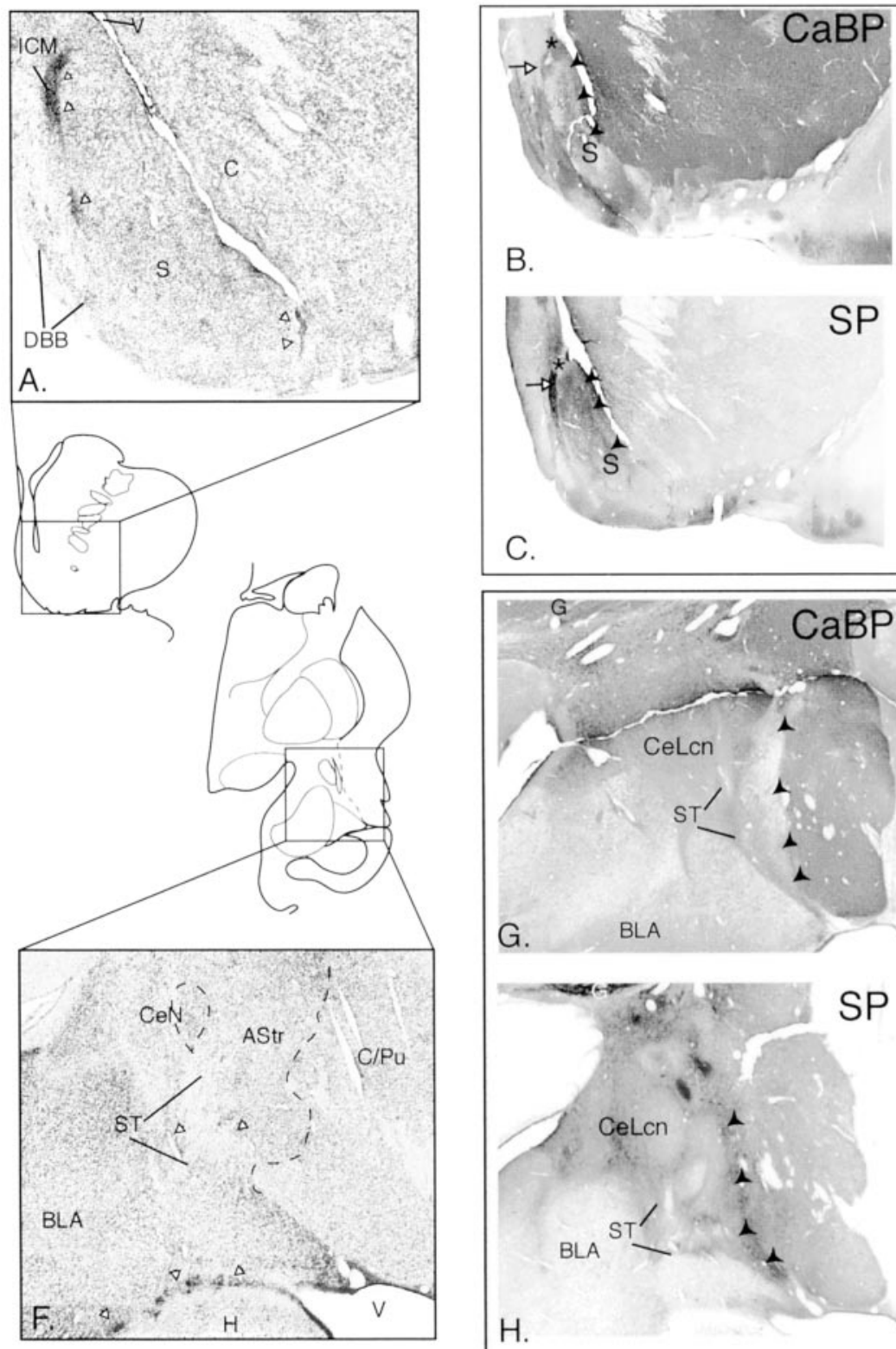

C.
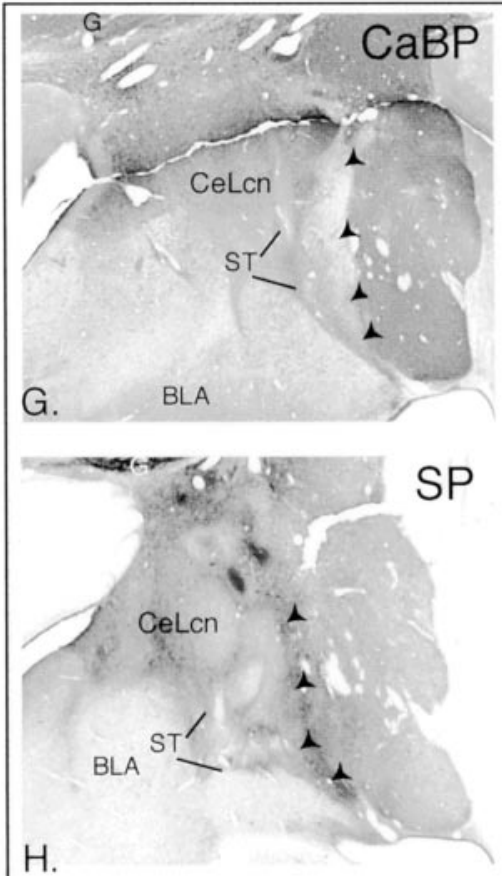

I.
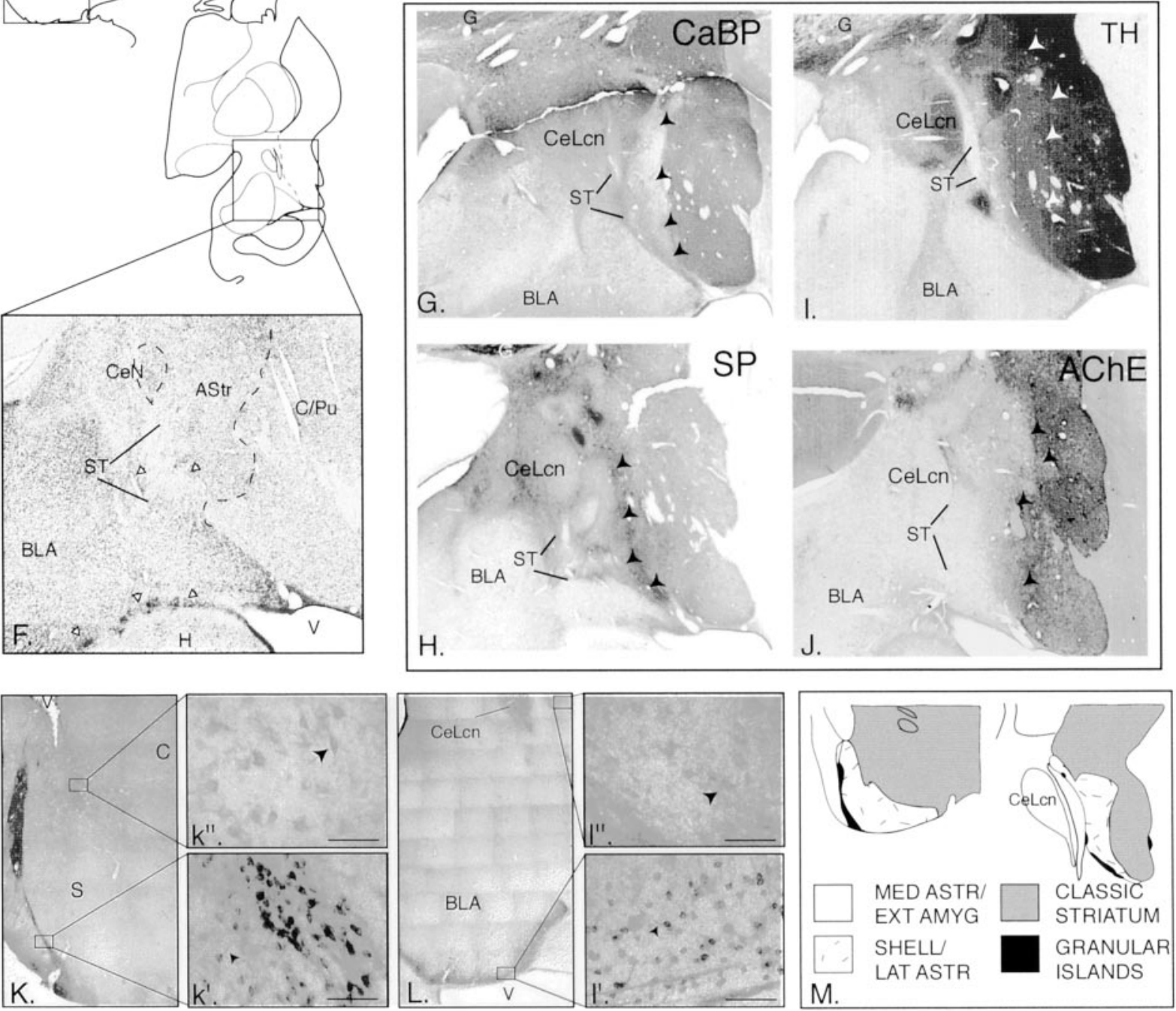

Figure 1. $A$, Nissl-stained sections through the ventral striatum. White arrowheads indicate the location of granule cell clusters. $C$, Core; $D B B$, diagonal band of Broca; $I C M$, island of Calleja magna; $S$, shell; $V$, ventricle. $B-E$, Ventral striatum stained for CaBP $(B)$, SP $(C)$, TH $(D)$, and AChE $(E)$. Arrowheads in $B$ and $D$ indicate the transition between shell and core. White arrows show the island of Calleja magna. Asterisk shows triangular zone at tip of dorsomedial shell that is high in $\mathrm{CaBP}$ and low in TH-SP-AChE. F, Nissl-stained sections through the amygdalostriatal area and caudoventral striatum. Fibers of the stria terminalis $(S T)$ divide the central amygdaloid nucleus $(C e N)$ and amygdalostriatal area $(A s t r)$. BLA, Basolateral nucleus of the amygdala; $C / P u$, caudate-putamen; $H$, hippocampus; $S T$, stria terminalis. $G-J$, The amygdalostriatal area-caudoventral striatum stained for $C a B P$ $(G)$, SP $(H)$, TH $(I)$, and AChE $(J)$. Arrowheads in $G$ and $H$ indicate the transition between shell and core. CeLcn, Lateral core, central nucleus; $G$, globus pallidus; $S T$, stria terminalis. $K, L$, Bcl-2 immunoreactivity in the ventral striatum $\left(K, k^{\prime}, k^{\prime \prime}\right)$ and caudal amygdala and amygdalostriatal area $(L$, $\left.l^{\prime}, l^{\prime \prime}\right)$. Scale bars, $50 \mu \mathrm{m}$. $M$, Components of the rostral and caudal ventral striatum. 
medium-sized cells with light cytoplasm, similar to the striatum outside the shell.

Substance $\mathrm{P}$ immunoreactivity throughout the amygdalostriatal area is relatively low (Fig. $1 H$ ). However, as in the ventral striatum, granular and parvicellular islands are associated with high substance P immunoreactivity, including substance P-positive woolly fibers. Similar to the pattern in the ventral striatum, a band of high SP immunoreactivity divides the CaBP-poor compartment from the CaBP-positive caudoventral striatum (Fig. $1 G, H$, arrowheads). Substance P levels are moderate in the caudoventral putamen and tail of the caudate nucleus, declining to low levels in more dorsal and lateral sectors.

$\mathrm{TH}$ and $\mathrm{AChE}$ staining in the medial amygdalostriatal area are generally very low, with several densely innervated patches corresponding to granular and/or parvicellular cell clusters (Fig. $1 I, J)$. In contrast, the lateral (CaBP-poor) amygdalostriatal area has more intense $\mathrm{AChE}$ and $\mathrm{TH}$ immunoreactivity. TH staining in this region is not clearly distinguishable from that in the caudoventral striatum. Intermediate AChE levels blend into high AChE levels in the striatum.

\section{Bcl-2 protein}

Bcl-2 staining is found in several cell types in both the rostral and caudal ventricular regions (Fig. $1 K, L$ ). Small, poorly differentiated cells $(6-10 \mu \mathrm{m})$ contain the highest levels of Bcl-2 staining and are concentrated in granular islands both rostrally and caudally (Fig. $1 k^{\prime}, l^{\prime}$ ). In the ventral striatum, small Bcl-2-positive cells fill the islands of Calleja. Caudally, this type of Bcl-2positive cell also is highly concentrated in the ventricular zone and widely dispersed in the fibers of the stria terminalis surrounding the amygdalostriatal area, the caudoventral striatum, and the amygdala. Although difficult to visualize individually because of their high packing density, some Bcl-2-positive cells have a single, wavy process (Fig. $1 k^{\prime}, l^{\prime}$, arrows). Small Bcl-2-positive cells in each region are associated with substance $\mathrm{P}$ - and TH-immunoreactive fibers. Somewhat larger Bcl-2-positive cells $(17-19 \mu \mathrm{m})$ are also found in the ventral striatum and amygdalostriatal area (Fig. $1 k^{\prime \prime}, l^{\prime \prime}$ ). These are more lightly stained and have the morphology of medium spiny neurons. In the ventral striatum, they are mainly seen in the shell at its transition with the core, whereas in the amygdalostriatal area, they are more diff usely scattered. A third, larger Bcl-2-positive cell occupies the encapsulated islands of the medial amygdalostriatal area $(16-26 \mu \mathrm{m})$ and central core of the central nucleus and bed nucleus of the stria terminalis (data not shown). Bcl-2-positive cells in these regions are fusiform with well developed dendritic trees.

\section{Overview of amygdalostriatal area-caudoventral striatum subdivisions}

The amygdalostriatal area and caudoventral striatum can be divided into three general zones based on cytoarchitectural and histochemical features: the medial amygdalostriatal area, the lateral amygdalostriatal area, and the caudoventral striatum (Fig. $1 M)$. The medial and lateral amygdalostriatal components fall within the traditional boundaries of the amygdalostriatal area. The medial amygdalostriatal area is distinguished by moderate to high CaBP staining, very low AChE, and generally low SP and TH staining. Encapsulated islands of medium-sized cells that are strongly immunoreactive for $\mathrm{CaBP}$ and $\mathrm{Bcl}-2$ also characterize this area. In contrast, the lateral amygdalostriatal area contains low CaBP immunoreactivity, moderate AChE activity, and relatively high $\mathrm{TH}$ levels. Substance P staining along the interface with the caudoventral striatum is high. The lateralmost component, the caudoventral striatum, has strong $\mathrm{CaBP}, \mathrm{AChE}$, and $\mathrm{TH}$ levels, comparable with that in the conventional striatum. Substance $\mathrm{P}$ staining is strong in the area bordering the lateral amygdalostriatal area but is moderate to low in other regions.

\section{DISCUSSION}

\section{The ventral striatum has a caudal continuum}

The concept of the ventral striatum originated with Heimer, who showed that the nucleus accumbens is part of the striatum based on its histologic features and inputs from the allocortex (Heimer and Wilson, 1975). Subsequent work showed that the nucleus accumbens, ventromedial caudate nucleus, and ventromedial putamen are included in the rostral ventral striatum, based on inputs from the amygdala and cortical areas mediating emotion and motivation (Haber and McFarland, 1999). The ventral striatal subregion known as the shell has emerged as a key feature of the ventral striatum over the last decade (Zahm and Brog, 1992). The shell is identified by relatively low $\mathrm{CaBP}$ levels and receives restricted inputs from limbic afferents, in contrast to the core, which receives broader projections (Brog et al., 1993; Haber and McFarland, 1999). Consistent with its unique anatomical connections, the shell is characterized by specific responses to motivational stimuli. For example, dopamine responses to salient cues show specific features in the shell compared with the core (Ahn and Phillips, 1999; Bassareo and Di Chiara, 1999) that are likely mediated by specific afferents, including selective inputs from the dorsal tier dopamine neurons.

In the present study, we demonstrate that there is a caudal analog of the ventral striatum based on histochemical and cellular criteria. This continuity is supported by connectional data, which show that the amygdala and cingulate, orbital, and superior temporal cortices project not only to the classic rostral ventral striatum but also to the caudoventral striatum and amygdalostriatal area (Russchen et al., 1985; Selemon and Goldman-Rakic, 1985; Fudge et al., 2001). Our data indicate that the caudal ventral striatum consists of the lateral amygdalostriatal area and caudoventral striatum based on the presence of markers AChE and $\mathrm{TH}$, which are a feature of the striatum across mammalian species (Sarnat and Netsky, 1981). Furthermore, a shell-like region exists in the lateral amygdalostriatal area, which contains smaller, more closely packed cells and weak CaBP immunoreactivity. The caudoventral striatum dorsal to this region is $\mathrm{CaBP}$ positive and contains medium-sized, less densely packed neurons, similar to the core. Substance $\mathrm{P}$ also has a distribution that is similar rostrally and caudally, with the highest levels bordering the transition between CaBP-poor and CaBP-rich zones. Bcl-2, a potent inhibitor of apoptosis and promoter of axonal growth (Zhong et al., 1993; Chen et al., 1997), is found mainly in the shell-like parts of the ventral striatum rostrally and caudally. This suggests that Bcl-2 may help form or maintain circuits mediating specific motivated responses.

\section{The relationship between the ventral striatum and the extended amygdala}

The shell is characterized by a close anatomical relationship to the central extended amygdala (CEA) at its rostral and caudal poles. The CEA includes the lateral bed nucleus of the stria terminalis (rostrally), the central amygdaloid nucleus (caudally), and the cell columns that join the two structures. Like the adjacent striatum, the lateral CEA contains medium spiny neurons and shares similar afferent inputs (Krettek and Price, 1978; Mc- 
Donald, 1982; Cassell et al., 1986; McDonald, 1991). These broad similarities have lead to debate as to whether the CEA is a separate macrostructure or is more properly considered part of the ventral striatum (Swanson and Petrovich, 1998; Zahm, 1998). Our data indicate that the medial amygdalostriatal area, which lies nearest to the central amygdaloid nucleus, is less striatal-like than the lateral amygdalostriatal area and caudoventral striatum based on overall low, patchy $\mathrm{TH}$ and AChE staining. Furthermore, this subregion contains relatively high homogeneous $\mathrm{CaBP}$ levels and encapsulated islands containing medium-size Bcl-2positive neurons. Both of these features are common to the core of central amygdaloid nucleus and bed nucleus of the stria terminalis. In contrast to the Bcl-2-immunoreactive cells of the ventral striatum, those in CEA and medial amygdalostriatal area are larger with well developed dendrites and show strong immunoreactivity. The encapsulated islands are considered part of the lateral central amygdaloid nucleus based on their low AChE staining and morphologic characteristics in human material (DeOlmos, 1990). Our results support this conclusion.

\section{Functional implications}

The ventral striatum has been traditionally associated with reward, and the extended amygdala has been associated with stress responses. However, recent work in both animals and humans shows that rewarding and stressful experiences can be mediated by both structures (Gallagher et al., 1990; Breiter et al., 2001; Reynolds and Berridge, 2001; Bassareo et al., 2002). Abnormal responses to positive and negative stimuli characterize many psychiatric diseases, in particular mood disorders. In depressive states, patients are hyperresponsive to negative stimuli and hyporesponsive to positive stimuli; in mania, the reverse is true. Mood-stabilizing drugs may exert their effects by upregulating plasticity-associated molecules, such as Bcl-2, in specific pathways (Manji and Lenox, 2000). The selective expression of Bcl-2 along the rostrocaudal extent of the CEA and shell-like ventral striatum suggests that pathways associated with these subterritories may be related to the effects of therapeutic drugs on stabilizing mood.

\section{REFERENCES}

Ahn S, Phillips AG (1999) Dopaminergic correlates of sensory-specific satiety in the medial prefrontal cortex and nucleus accumbens of the rat. J Neurosci 19:RC29(1-6).

Bassareo V, Di Chiara G (1999) Differential responsiveness of dopamine transmission to food-stimuli in nucleus accumbens shell/core compartments. Neuroscience 89:637-642.

Bassareo V, De Luca MA, Di Chiara G (2002) Differential expression of motivational stimulus properties by dopamine in nucleus accumbens shell versus core and prefrontal cortex. J Neurosci 22:4709-4719.

Bernier PJ, Parent A (1998) Bcl-2 protein as a marker of neuronal immaturity in postnatal primate brain. J Neurosci 18:2486-2497.

Breiter HC, Aharon I, Kahneman D, Dale A, Shizgal P (2001) Functional imaging of neural responses to expectancy and experience of monetary gains and losses. Neuron 30:619-639.

Brog JS, Salyapongse A, Deutch AY, Zahm DS (1993) The patterns of afferent innervation of the core and shell in the "accumbens" part of the rat ventral striatum: Immunohistochemical detection of retrogradely transported fluoro-gold. J Comp Neurol 338:255-278.

Cador M, Robbins TW, Everitt BJ (1989) Involvement of the amygdala in stimulus-reward associations: interaction with the ventral striatum. Neuroscience 30:77-86.

Cassell MD, Gray TS, Kiss JZ (1986) Neuronal architecture in the rat central nucleus of the amygdala: a cytological, hodological, and immunocytochemical study. J Comp Neurol 246:478-499.

Chen DF, Schneider GE, Martinou JC, Tonegawa S (1997) Bcl-2 promotes regeneration of severed axons in mammalian CNS. Nature $385: 434-439$.

DeOlmos JS (1990) Amygdala. In: The human nervous system (Paxinos G, ed), pp 583-710. San Diego: Academic.

Fallon JH, Loughlin SE, Ribak CE (1983) The islands of Calleja complex of rat basal forebrain. III. Histochemical evidence for a striatopallidal system. J Comp Neurol 218:91-120.
Freedman LJ, Shi C (2001) Monoaminergic innervation of the macaque extended amygdala. Neuroscience 104:1067-1084.

Fudge JL, Kunishio K, Walsh P, Richard C, Haber SN (2002) Amygdaloid projections to ventromedial striatal subterritories in the primate. Neuroscience 110:257-275.

Gallagher M, Graham PW, Holland PC (1990) The amygdala central nucleus and appetitive Pavlovian conditioning: lesions impair one class of conditioned behavior. J Neurosci 10:1906-1911.

Geneser-Jensen FA, Blackstad TW (1971) Distribution of acetyl cholinesterase in the hippocampal region of the guinea pig. Z Zellforsch Mikrosk Anat 114:460-481.

Haber SN, McFarland NR (1999) The concept of the ventral striatum in nonhuman primates. In: Advancing from the ventral striatum to the extended amygdala (McGinty JF, ed), pp 33-48. New York: New York Academy of Sciences.

Haber SN, Nauta WJH (1983) Ramifications of the globus pallidus in the rat as indicated by patterns of immunohistochemistry. Neuroscience 9:245-260.

Hedreen JC (1981) Neurons of the nucleus accumbens and other striatal regions in rats. In: Neurobiology of the nucleus accumbens (DeFrance RB, ed), pp 82-96. Brunswick, ME: The Haer Institute for Electrophysiologic Research.

Heimer L, Wilson RD (1975) The subcortical projections of the allocortex: similarities in the neural associations of the hippocampus, the piriform cortex, and the neocortex. In: Golgi centennial symposium: perspectives in neurobiology (Santini M, ed), pp 177-193. New York: Raven.

Heimer L, De Olmos JS, Alheid GF, Person J, Sakamoto N, Shinoda K, Marksteiner J, Switzer RC (1999) The human basal forebrain, Pt II. In: Handbook of chemical neuroanatomy (Bloom FE, Bjorkland A, Hokfelt T, eds), pp 57-226. Amsterdam: Elsevier.

Holt DJ, Hersh LB, Saper CB (1996) Cholinergic innervation in the human striatum: a three-compartment model. Neuroscience 74:67-87.

Holt DJ, Graybiel AM, Saper CB (1997) Neurochemical architecture of the human striatum. J Comp Neurol 384:1-25.

Krettek JE, Price JL (1978) Amygdaloid projections to subcortical structures within the basal forebrain and brainstem in the rat and cat. J Comp Neurol 178:225-254.

Manji HK, Lenox RH (2000) Signaling: cellular insights into the pathophysiology of bipolar disorder. Biol Psychiatry 48:518-530.

Martin LJ, Hadfield MG, Dellovade TL, Price DL (1991) The striatal mosaic in primates: Patterns of neuropeptide immunoreactivity differentiate the ventral striatum from the dorsal striatum. Neuroscience 43:397-417.

McDonald AJ (1982) Cytoarchitecture of the central amygdaloid nucleus of the rat. J Comp Neurol 208:401-418.

McDonald AJ (1991) Topographical organization of amygdaloid projections to the caudatoputamen, nucleus accumbens, and related striatallike areas of the rat brain. Neuroscience 44:15-33.

Meredith GE, Pattiselanno A, Groenewegen HJ, Haber SN (1996) Shell and core in monkey and human nucleus accumbens identified with antibodies to calbindin-D28k. J Comp Neurol 365:628-639.

Meyer G, Gonzalez-Hernandez T, Carrillo-Padilla F, Ferres-Torres R (1989) Aggregations of granule cells in the basal forebrain (islands of Calleja): Golgi and cytoarchitectonic study in different mammals, including man. J Comp Neurol 284:405-428.

Millhouse OE (1987) Granule cells of the olfactory tubercle and the question of the islands of Calleja. J Comp Neurol 265:1-24.

Pitkanen A, Amaral DG (1993) Distribution of calbindin-D28k immunoreactivity in the monkey temporal lobe: the amygdaloid complex. J Comp Neurol 331:199-224.

Reynolds SM, Berridge KC (2001) Fear and feeding in the nucleus accumbens shell: rostrocaudal segregation of GABA-elicited defensive behavior versus eating behavior. J Neurosci 21:3261-3270.

Russchen FT, Bakst I, Amaral DG, Price JL (1985) The amygdalostriatal projections in the monkey. An anterograde tracing study. Brain Res 329:241-257.

Sarnat H, Netsky M (1981) Telencephalon. In: Evolution of the nervous system, pp 321-378. New York: Oxford UP.

Selemon LD, Goldman-Rakic PS (1985) Longitudinal topography and interdigitation of corticostriatal projections in the rhesus monkey. J Neurosci 5:776-794.

Swanson LW, Petrovich GD (1998) What is the amygdala? Trends Neurosci 21:323-331

Voorn P, Brady LS, Schotte A, Berendse HW, Richfield EK (1994) Evidence for two neurochemical divisions in the human nucleus accumbens. Eur J Neurosci 6:1913-1916.

Zahm DS (1998) Is the caudomedial shell of the nucleus accumbens part of the extended amygdala? A consideration of connections. Crit Rev Neurobiol 12:245-265.

Zahm DS, Brog JS (1992) On the significance of subterritories in the "accumbens" part of the rat ventral striatum. Neuroscience 50:751-767.

Zhong LT, Sarafian T, Kane DJ, Charles AC, Mah SP, Edwards RH, Bredesen DE (1993) bcl-2 inhibits death of central neural cells induced by multiple agents. Proc Natl Acad Sci USA 90:4533-4537. 